\title{
JUSTIÇA RESTAURATIVA E ASSÉDIO MORAL
}

\author{
RESTORATIVE JUSTICE AND HARASSMENT IN THE WORKPLACE
}

JUSTICIA RESTAURATIVA Y ACOSO MORAL

Licença CC BY:

Artigo distribuído sob os termos Creative

Commons, permite uso e distribuição irrestrita em qualquer meio desde que o autor credite a fonte original.

\section{Marcos Rolim ${ }^{1}$}

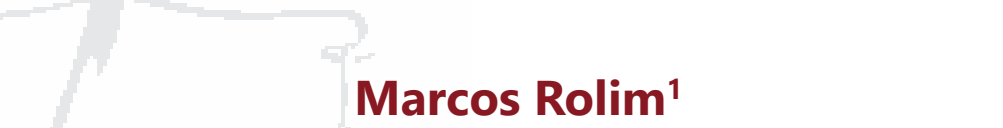

Resumo: $O$ artigo discute as possibilidades da aplicação da justiça restaurativa para a superação de conflitos no ambiente de trabalho, notadamente para as dinâmicas que envolvem assédio moral. $O$ texto relata os resultados de estudo de revisão, cuja metodologia envolveu a busca online em plataformas acadêmicas e em revistas científicas de artigos publicados em inglês e português a respeito do tema. A abordagem da restauração é situada com um método para a superação de conflitos, mas também como um conjunto de valores. Os limites do Direito Penal são referidos, destacando-se a necessidade de se encontrar, sempre que possível, formas alternativas e efetivas de resolução de conflitos. O estudo encontrou evidências que sugerem que a justiça restaurativa pode ser empregada com êxito nos ambientes de trabalho para superar casos de assédio moral e para criar um ambiente de prevenção a esse tipo de ocorrências.

Palavras-chave: Justiça restaurativa, limites do Direito Penal, assédio moral no trabalho.

Abstract: The article discusses the possibilities of applying restorative justice to overcome conflicts in the workplace, especially due to their dynamics, which involve moral harassment. The text reports the results of a review study, the methodology of which involved searching online, on academic platforms and in scientific journals, for articles on the subject published in English and Portuguese. The restoration approach is a method for overcoming conflicts, but also a set of values. The limits of Criminal Law are mentioned, highlighting the need to find alternative and effective forms of conflict resolution wherever possible. The study found evidence to suggest that restorative justice can be successfully used in the workplace to overcome cases of harassment and create an environment for preventing such occurrences.

Keywords: Restorative Justice, Limits of Criminal Law, Harassment in the Workplace.

1 Doutor e mestre em Sociologia, professor do mestrado em Direitos Humanos do Centro Universitário Ritter dos Reis (UniRitter), Porto Alegre, RS, Brasil. marcos@rolim.com.br 
Resumen: El artículo discute las posibilidades de la aplicación de la justicia restaurativa para la superación de conflictos en el ambiente de trabajo, notadamente para las dinámicas que envuelven acoso moral. El texto relata los resultados del estudio de revisión, cuya metodología envolvió la búsqueda online en plataformas académicas y en revistas científicas de artículos publicados en inglés y portugués con relación al tema. El abordaje de la restauración es situada con un método para la superación de conflictos, pero también como un conjunto de valores. Los límites del Derecho Penal son mencionados, destacándose la necesidad de encontrarse, siempre que posible, formas alternativas y efectivas de resolución de conflictos. El estudio encontró evidencias que sugieren que la justicia restaurativa puede ser empleada con éxito en los ambientes de trabajo para superar casos de acoso moral y para crear un ambiente de prevención a ese tipo de incidentes.

Palabras clave: Justicia restaurativa, límites del Derecho Penal, acoso moral en el trabajo.

\section{INTRODUÇÃO}

Algo muito particular ocorre em nossa época com os sentidos mais comuns atribuídos à expressão "Justiça". Em que pese a polissemia pressuposta pelo conceito, "Justiça" tem sido um ideal cada vez mais concebido a partir do paradigma do Direito Penal. Tanto na forma como a mídia trata a ideia de Justiça, quanto no senso comum, o que se percebe é que a "Justiça" tem sido associada a uma técnica determinada pela qual se assegura como resultado a imposição de uma pena. Obtida a esperada condenação criminal, se compreende que "a Justiça foi praticada". Tão forte é essa associação que as justas absolvições - outro tipo de resultado inerente ao processo criminal - são quase sempre traduzidas como "impunidade", o que significaria que, nesses casos, estaríamos diante da ausência de "Justiça".

O processo, que expressa a forte demanda punitiva experimentada em realidades sociais marcadas pela violência e pela corrupção, termina por amesquinhar o generoso ideal da Justiça. Como consequência, vamos perdendo os sentidos emancipatórios apontados por muitos autores, desde Aristóteles $^{2}$ que vinculou a ideia de Justiça às virtudes da cidade, ressaltando a "igualdade", princípio assentado na integridade moral (Dikaiosyne); passando por Benthan ${ }^{3}$ e os utilitaristas para quem a Justiça estava definida pela promoção da "felicidade"; por Rawls4 e a noção de Justiça como "equidade"; por Maclntyre ${ }^{5}$ que sustenta a Justiça como o equivalente à "afirmação do bem" ou Dworkin" para quem a Justiça deve ser compreendida como "igual cuidado e responsabilidade especial", para citar apenas alguns dos caminhos mais produtivos.

O paradigma da Justiça restaurativa oferece uma abordagem distinta daquela do Direito Penal, o que configura uma primeira grande dificuldade diante da noção mais amplamente disseminada a respeito de como se deve tratar pessoas que praticam atos ilegais. Fora da moldura do Direito Penal, tornou-se difícil até mesmo falar em crime. Para a Justiça restaurativa, entretanto, é possível e

2 ARISTÓTELES. Ética a Nicômaco. Brasília: UNB, 2001.

3 BENTHAM, Jeremy. Os pensadores. São Paulo: Abril Cultural, 1979.

4 RAWLS, John, Uma Teoria da Justiça, São Paulo: Martins Fontes, 1997.

5 MACINTYRE, Alasdaire. After Virtue: A Study in Moral Theory. Notre Dame, University of Notre Dame Press. 1984.

6 DWORKIN, Ronald. Levando os direitos a sério. São Paulo: Martins Fontes, 2010. 
necessário se falar em violência, em crime e em atos desrespeitosos ou que produzem sofrimento a partir de outro local que não o Código Penal, o que deve ser alcançado a partir do protagonismo das partes envolvidas e da comunidade afetada.

A abordagem da Justiça restaurativa pode ser empregada muito amplamente, sempre que estamos diante de conflitos com partes identificáveis que tenham a disposição de participar. Isso poderia valer, também, para casos de assédio moral e para as dinâmicas no ambiente de trabalho que podem conduzir a esse fenômeno de tão graves consequências? Nossa hipótese de pesquisa indicava que sim. Para discutir o tema, realizamos um estudo de revisão a partir da procura em plataformas acadêmicas e em revistas científicas de artigos a respeito do tema específico, com destaque para aqueles que apresentavam avaliações de resultados de projetos com justiça restaurativa no ambiente de trabalho.

Neste texto, iniciamos situando os sentidos da restauração e abordando alguns dos limites do Direito Penal. Ato contínuo, mostramos a gravidade e a importância do fenômeno do assédio moral no ambiente de trabalho, ainda hoje subestimado no Brasil, para, então, sustentar que as relações e dinâmicas no ambiente de trabalho constituem um espaço ainda pouco explorado, mas, aparentemente, muito promissor, para a abordagem restaurativa.

\section{A ABORDAGEM RESTAURATIVA}

Quando falamos em justiça restaurativa, nos referimos a um método específico de superação de conflitos cuja ideia central - aquela que acompanha as diferentes visões sobre a própria restauração - envolve a construção de um espaço de encontro, reconhecimento e responsabilização que irá conectar os envolvidos pelo crime ou ato indesejável, com ênfase na vítima.

A justiça restaurativa coloca as vítimas e os autores em contato, assim, as vítimas podem responder questões, dizer aos autores qual o impacto real que o crime produziu e receber desculpas. A justiça restaurativa oferece aos autores a chance de repararem seu crime, frente às próprias vítimas, ou frente à comunidade. Mas a justiça restaurativa é mais do que reparação material - ela pode reparar os relacionamentos e a confiança que foram rompidos com o crime (tradução do autor) ${ }^{7}$.

Ao invés do processo de busca do responsável pelo delito e da imposição de medidas proporcionais de dor (a pena), a justiça restaurativa busca a recomposição do equilíbrio existente antes do crime, ou antes do ato indesejável e produtor de sofrimento, através de um encontro entre as partes envolvidas e a comunidade, de tal modo que se produza um acordo em torno de

$7 \quad$ HOME OFFICE, Restorative Justice: the Government's Strategy, A consultation document on the Government Strategy on Restorative Justice, London: Home Office, 2003, apud: TICKELL Shari and AKESTER, Kate.

Restorative Justice, the way ahead. Justice publication, London, 2004, pp. 12-13. 
atitudes a serem tomadas pelo autor em favor da vítima. Para Braithwaite ${ }^{8}$ o objetivo central da justiça restaurativa é o de curar relacionamentos, ao invés de equilibrar a dor com a dor.

O "equilíbrio" existente antes do crime, entretanto, não é uma realidade empírica, mas uma ideia reguladora pela qual pressupomos a afirmação da Justiça. A lembrança permite compreender, por exemplo, como a África do Sul de Mandela foi capaz de tratar os bárbaros crimes do regime do apartheid com os procedimentos restaurativos da Comissão de Verdade e Reconciliação ${ }^{9}$. Naquele processo, por óbvio, não se tratava de restaurar o equilíbrio injusto do racismo, mas, pelo contrário, de superar sua memória de dor pela esperança que brota da verdade e do reconhecimento.

A justiça restaurativa começa no desequilíbrio dos relacionamentos em sociedade, mas o que será restaurado não é a faticidade desses relacionamentos antes da ruptura, mas um relacionamento ideal de igualdade na sociedade, um ideal que sobrevive - pelo menos enquanto ideal - quando os direitos básicos como a segurança das pessoas são respeitados mesmo em um contexto de injustiça social (tradução do autor) ${ }^{10}$.

Nesse caminho, embora autores e vítimas sejam os sujeitos, a vítima assume a centralidade do processo restaurativo e o que se busca é o encerramento do conflito por um pacto capaz de satisfazê-la. Trata-se, assim, de um processo de responsabilização não criminal que pode viabilizar o reconhecimento entre as partes e o cumprimento de um acordo construído livremente pelo qual o autor fará algo para que as consequências de seu gesto sejam superadas ou, pelo menos, minimizadas. Para Marshal11, justiça restaurativa é "um processo onde as partes envolvidas por um determinado erro ou delito encontram-se para resolver coletivamente como lidar com as consequências do fato e com suas implicações futuras".

A abordagem, que tem sido aplicada em muitos países, não se restringe aos fatos descritos pela legislação penal. A rigor, pode-se aplicar justiça restaurativa a todos os conflitos onde existam partes identificadas, desde que elas estejam dispostas ao processo. Há como desenvolver projetos restaurativos nas escolas, na educação dos filhos, nas relações entre policiais e a cidadania e, inclusive, nas prisões, ao longo da execução penal. Muitas são as evidências que apoiam o emprego de práticas

8 BRAITHWAITE, J. Restorative justice and corporate regulation, in: Weitekamp, G.M. and Herner, H.-J. (Eds), Restorative Justice in Context: International Practice and Directions, Willan Publishing, Portland, OR, 2003, pp. 161-72.

9 SOUTH AFRICA. Truth and reconciliation commission. Report, vol. 1 e 2. Presented to President Nelson Mandela on 29 October 1998. Disponíveis, respectivamente, em: https://www.sahistory.org.za/sites/default/files/ volume_1_1.pdf e em https://www.justice.gov.za/trc/report/finalreport/Volume\%202.pdf Acesso: 17/07/2019.

10 LLEWELLYYN, Jennifer J. and HOWSE, Robert. Restorative Justice: a Conceptual Framework, prepared for the Law Commission of Canada, 1999. https://papers.ssrn.com/sol3/papers.cfm?abstract_id=2114291 . Acesso em:17/10/2019.

11 MARSHALL, F. Alternatives to Criminal Courts: The Potential For Non-Judicial Dispute Settlemen. Brookfield, VT: Gower Publishing Co., 1985. 
restaurativas em diferentes instituições, especialmente em escolas ${ }^{12,13,14}$. Os resultados obtidos com a abordagem, no mais, tendem a satisfazer as partes e a produzir efeitos preventivos importantes. As avaliações mostram que as vítimas se sentem melhor já desde o primeiro momento, quando conseguem relatar o seu sofrimento e as suas dificuldades em uma reunião onde todos a ouvem com atenção ${ }^{15,16}$ os autores, ao mesmo tempo, se dão conta, verdadeiramente, dos danos que causaram e o relato do sofrimento imposto às vítimas os estimula a assumir compromissos de reparação ${ }^{17}$.

Ao contrário do Direito Penal, entretanto, a restauração pressupõe a voluntariedade. Não há como se obrigar as partes a participar da Justiça restaurativa, pela simples razão de que essa circunstância aniquilaria seus pressupostos. Os procedimentos restaurativos só podem funcionar se as partes estiverem comprometidas com a verdade, se forem capazes de verbalizar seus sentimentos, se forem respeitosas na discussão e se estiverem preparadas para um compromisso de reparação. Disposições do tipo não são asseguradas pela Lei, mas pela consciência.

A característica de voluntariedade dos processos restaurativos permite compreender as razões pelas quais essa abordagem não tem a pretensão de substituir o Direito Penal. A restauração, pelo contrário, precisa - em alguma dimensão pelo menos - do Direito Penal. Conclusão que conduziu autores ${ }^{18}$ a sustentar, por exemplo, que deva se trabalhar no sentido de uma integração entre os dois sistemas, criminal e restaurativo, de tal forma que se possa manter, do primeiro, seus procedimentos, padrões e garantias e, do segundo, seus objetivos.

Os motivos para essa convivência necessária ligam-se, primeiro, por óbvio, à necessidade de que não se produza a impunidade sobre os recalcitrantes e, segundo, para que as partes percebam com mais clareza as vantagens comparativas. No caso dos acusados pela prática de um crime, a oferta de um processo restaurativo se faz, nos países onde as legislações assim o permitem, a partir da suspensão condicional do processo criminal. Aceitar a participação em um processo restaurativo nessa hipótese - onde o acusado se coloca na posição de autor - não poderá ser utilizado como prova contra ele em eventual retomada do processo penal. A retomada, por seu turno, ocorrerá sempre que uma das partes desista da restauração, quando não se alcançar um acordo e nos casos em que o compromisso firmado não for honrado.

12 JOHNSTONE, Gerry. Restorative Justice: Ideas, Values, Debates. New York, Routledge, 2011.

13 NUGENT, William R, WILLIAMS, Mona \& UMBREIT, Mark S. Participation in Victim Offender Mediation and the Prevalence and Severity of Subsequent Delinquent Behavior: A Meta-Analysis. Utah Law Review, 137, 2003.

14 BRADSHAW, William, ROSEBOROUGH, David and UMBREIT, Mark S. The Effect of Victim Offender Mediation on Juvenile Offender Recidivism: A Meta-Analysis, Conflict Resolution Quarterly, Volume 24, Issue 1, 2006, pp 87-98.

15 MCCULLOUGH, M.E., RACHAL, K.C., SANDAGE, S.J., WORTHINGTON, E.L. JR, BROWN, S.W. and HIGHT, T.L. Interpersonal forgiving in close relationships: II. Theoretical elaboration and measurement, Journal of Personality and Social Psychology, Vol. 75, 1998, pp. 1586-603.

16 STRANG, H. Repair or Revenge: Victims and Restorative Justice. Clarendon Press, Oxford, 2002.

17 UMBREIT, M.S. The Handbook of Victim Offender Mediation. Jossey-Bass, San Francisco, CA, 2001.

18 HUDSON, Barbara, MCEVOY, Kieran e MIKA, Harry. Introduction: Practice, Performance and Prospects for Restorative Justice, British Journal of Criminology, 42, 2002, pp.469-475. Disponível em: https://goo.gl/ FhRmjC. Acesso em: 28/12/2019. 
Já o Direito Penal prescinde da abordagem restaurativa e, de fato, tem vivido por séculos, de forma independente, sem demandar outras técnicas ou meios de superar conflitos. Quando o Direito Penal perfaz o seu ciclo e aplica a pena ao acusado, é como se todas as demais formas de tratamento se tornassem impossíveis. Zaffaroni ${ }^{19}$ chama a atenção para essa dimensão lançando mão da analogia do menino que quebrou uma vidraça na escola. Nesse caso, os pais poderiam ser chamados para pagar o dano; a escola poderia encaminhar o menino a um psicopedagogo ou conversar com ele para saber se alguém ou algo lhe fez mal. Cada uma dessas respostas é plenamente legítima, elas podem ser aplicadas de forma isolada ou conjuntamente e não envolvem a ideia de punir o responsável. Entretanto, assinala o autor, se a direção resolver punir o menino, expulsando-o da escola, por exemplo, então nenhuma das alternativas mencionadas poderia ser aplicada.

\section{OS LIMITES DO DIREITO PENAL}

Ao considerarmos as possibilidades da justiça restaurativa, vale dizer, as chances reais de superação de conflitos e de reparação do mal causado por meio de compromissos firmados livremente entre as partes, devemos ter em conta também os limites do Direito Penal e os efeitos criminogênicos derivados da prisão, notadamente aqueles que se tornaram comuns nas experiências de encarceramento em massa.

Para o paradigma do Direito Penal, se mede a eficácia dos processos pela quantidade de condenações criminais, vale dizer, pela quantidade de dor imposta aos acusados. Para avaliar esse modelo, entretanto, seria preciso considerar todos seus efeitos. Em primeiro lugar, se deveria ter em mente a "cifra de ineficiência" e a "cifra de injustiça" inerentes ao sistema20.

Ao que os sociólogos denominam cifra obscura da criminalidade (dark rate, formada pelos crimes não reportados à polícia e, portanto, desconhecidos) é preciso acrescentar uma cifra não menos obscura, porém mais inquietante e intolerável: aquela formada pelo número de inocentes processados e, por vezes, condenados. Chamarei cifra de ineficiência a primeira dessas cifras e cifra de injustiça a segunda, na qual se incluem: a) os inocentes reconhecidos como tais em sentenças de absolvição após haverem sofrido processo penal e, em ocasiões, prisão preventiva; b) os inocentes condenados por sentença judicial e ulteriormente absolvidos por conta de um procedimento de revisão; c) as vítimas, cujo número jamais se poderá calcular - verdadeira cifra obscura da injustiça - dos erros judiciais não reparados... (Tradução do autor).

Pouca importância se confere à dimensão da injustiça que consiste na execração pública de alguém inocente. O fato é que o processo penal já constitui um tipo especial de punição, o que é particularmente exasperante para os que não possuem responsabilidade pelo crime que se pretende

19 ZAFFARONI, Eugenio Raúl. A questão criminal. Rio de Janeiro:Revan, 2013.

20 FERRAJOLI, Luigi. Derecho y Razón, Teoria del Garantismo Penal. Madrid, Editorial Trotta, 1977, p. 210. 
esclarecer. Uma parte dos injustamente acusados será condenada, aumentando a quota de injustiça do sistema. Se poderia ainda acrescentar que, entre os que realmente cometeram os delitos pelos quais foram acusados, teremos uma parte que não será condenada, porque não se conseguiu a prova robusta. Embora, em situações do tipo, o sistema tenha funcionado segundo suas premissas garantidoras, a circunstância assinala outra injustiça. Por fim, teremos ainda duas partes adicionais de injustiça, representadas pelos que foram condenados a penas maiores do que aquelas que, de fato, deveriam ter recebido e por aqueles que, pelo contrário, tiveram suas penas equivocadamente mitigadas. Nesse quadro, o percentual dos condenados com prova robusta (para além de qualquer dúvida razoável) e que receberam sentenças justas talvez seja pequeno demais para ser considerado. A sensação que se tem, como alguém já observou, é que, para a grande maioria dos delitos, o Direito Penal é excessivo, enquanto que, para os crimes mais graves, parece inútil.

A imposição de penas privativas de liberdade tem se revelado, no mais, medida nada eficiente e, não raro, disfuncional. O chamado "efeito dissuasório das penas" é a promessa central do Direito Penal que jamais foi cumprida. É possível e necessário se reduzir a violência e a criminalidade, mas quem imaginar que a resposta mais efetiva do Estado a esses problemas deva ser o encarceramento corre o risco de ver sua receita agravar e ampliar aquelas mazelas em curto espaço de tempo. Essa é, aliás, a dinâmica que estamos presenciando no Brasil há algumas décadas.

A política criminal em curso criou uma demanda de encarceramento em massa que nos levou a superar a marca dos 750 mil presos ${ }^{21}$, com um déficit estimado - de forma conservadora - em 354 mil vagas ${ }^{22}$. Prisões superlotadas são ótimos espaços para a organização criminal, porque as condições de alojamento inviabilizam a separação dos presos, a individualização das penas e qualquer execução penal decente. A superlotação leva à contenção coletiva de centenas de pessoas em galerias, o que obriga as administrações prisionais a separarem os presos pelo "critério" do pertencimento a facções. Uma primeira consequência desse tipo de ilegalidade é que os condenados precipitam e reforçam seus vínculos criminais, agora sob comandos centralizados. Uma segunda consequência é que as facções não precisam mais se preocupar em recrutar novos membros, o Estado passa a fazer isso para elas.

Não bastasse esse efeito, o processo de criminogênese em curso se desdobra, como se sabe, para além das penas. Seria preciso considerar que as penas de prisão são medidas aflitivas não apenas para os condenados, mas também para seus familiares. Esse poderia ser o custo a ser pago para os casos de pessoas que praticaram crimes com grave violência e que destruíram a felicidade de famílias inteiras. Caso as prisões fossem reservadas para os autores desse tipo de crime, seria possível identificar, inclusive, um efeito de neutralização importante capaz de reduzir casos graves de violência. Ocorre que, no Brasil, esse não é o perfil das pessoas que prendemos. A grande maioria

21 BRASIL. Ministério da Justiça e Segurança Pública. Departamento Penitenciário Nacional (Depen), DF, 2020. Disponível em: https://www.gov.br/depen/pt-br/assuntos/noticias/depen-lanca-dados-do-sisdepen-do-primeirosemestre-de-2020\#: :text=Bras\%C3\%ADlia\%2C\%2015\%2F10\%2F2020,penitenci\%C3\%A1 rio\%20brasileiro\%20 \%C3\%A9\%20de\%20759.518. Acesso em 20/10/2020.

22 BRASIL. Conselho Nacional de Justiça (CNJ), DF, Cidadania nos Presídios, s/d. Disponível em: https://www.cnj. jus.br/sistema-carcerario/cidadania-nos-presidios/ 
delas, como se sabe, não cumprem penas por crimes praticados com violência real. Entretanto, o custo mencionado é pago por todos os presos, condenados ou não, independente do delito que tenham cometido ou daquele pelo qual tenham sido acusados. Um dos resultados desse processo é o estímulo ao crime intergeracional $23,24,25$ :

Por fim, quando os egressos que resistiram à organização das facções buscam colocação no mercado de trabalho, enfrentam outro tipo de condenação, essa de natureza moral e perpétua. Para eles, efetivamente, não haverá chances. O estigma social sobre os condenados, pessoas "desacreditadas"26, é tamanho que, muitas vezes, a simples notícia da prisão é motivo suficiente para que inclusive seus familiares percam seus empregos. O problema é conhecido em todo o mundo e as evidências disponíveis mostram que os egressos que se esforçam na procura de trabalho dificilmente conseguem a almejada reintegração. Estudo ${ }^{27}$ sobre o impacto da prisão nas taxas de desemprego nos EUA, por exemplo, mostrou que a exclusão dos egressos do mercado de trabalho custa aos americanos algo entre 57 a 65 bilhões de dólares ao ano. Em países como o Brasil, é provável que os efeitos produtores do crime e da violência derivados do estigma social sejam muito mais pronunciados, seja porque a carga de preconceito é maior, seja porque nos ressentimos de políticas públicas de ressocialização e de apoio aos egressos.

\section{O ASSÉDIO MORAL NO TRABALHO}

O assédio moral no espaço do trabalho tem sido definido pela experiência de sofrimento psicológico imposta aos subordinados, tornada comum pela repetição de situações de humilhação ou constrangimento orientadas, quase sempre, pelo objetivo de forçar a vítima à desistência do emprego. As situações que podem caracterizar o assédio moral são muito variadas. Segundo Duncan ${ }^{28}$, mas é comum que envolvam práticas repetidas de a) críticas injustificadas ou inválidas; b) atribuição de culpa sem base factual; c) tratamento distinto dos demais colegas; d) ameaça; e) isolamento; f) humilhação e desrespeito; g) chacotas e h) excessivo monitoramento. A incidência do fenômeno é epidêmica. Pesquisa realizada nos EUA em 2007, por exemplo, encontrou 54 milhões de

23 FARRINGTON, David. P. Families and crime. In: J.Q. Wilson \& J. Petersilia (eds.) Crime and public policy. Oxford University Press, 2011, pp. 130-157.

24 VAN DE RAKT, M.G.A. Two Generations of Crime: The Intergenerational Transmission of Criminal Convictions over the Life Course, Dissertation Radboud University Nijmegen, the Netherlands, 2011. Disponível em: <https:// www.mariekevanderakt.nl/wp-content/uploads/2011/07/Two-Generations-of-Crime.pdf>. Acesso em: 18/11/2019.

25 BESEMER, Sytske and FARRINGTON, David P. Intergenerational transmission of criminal behaviour: Conviction trajectories of fathers and their children. European Journal of Criminology, Volume: 9 issue: 2, 2012, pp. 120141. Disponível em: <http://journals.sagepub.com/doi/pdf/10.1177/1477370811422801>. Acesso em: 05/01/2020.

26 GOFFMAN, E. Estigma: notas sobre a manipulação da identidade deteriorada. Rio de Janeiro: LTC, 1988.

27 SCHMITT, John and WARNER, Kris. Ex-offenders and the Labor Market. Washington, D.C. Center for Economic and Policy Research, 2010. Disponível em: <http://cepr.net/documents/publications/ex-offenders-2010-11.pdf>. Acesso em: 18/11/2019.

28 WORKPLACE BULLYING SURVEY, 2007, apud DUNCAN, Susan. Workplace Bullying and the Role Restorative Practices Can Play in Preventing and Addressing the Problem. Industrial Law Journal, Vol. 32, 2011, pp. 233167. Disponível em: <https://papers.ssrn.com/sol3/papers.cfm?abstract_id=1916138>. Acesso em: 05/01/2020. 
trabalhadores afetados, aproximadamente $37 \%$ da força de trabalho ${ }^{29}$. Estudo ${ }^{30}$ com trabalhadores estadunidenses estimou que 35\% a 50\% deles têm uma experiência negativa no local de trabalho por semana envolvendo conflitos variados. Em outro trabalho ${ }^{31}$ se encontrou que $90 \%$ dos trabalhadores enfrentam pelo menos um episódio de assédio moral em seu emprego ao longo de suas carreiras.

Para Leymann ${ }^{32}$, deve-se compreender o assédio moral como:

(....) comunicação hostil e antiética dirigida de forma sistemática por uma ou várias pessoas, mais comumente em direção a uma pessoa. Há também casos em que o mobbing é mútuo até que um dos participantes se torne o perdedor. Essas ações ocorrem frequentemente (quase todos os dias) e durante um longo período (pelo menos durante seis meses) e, devido a esta frequência e duração, resulta em grande sofrimento psíquico, psicossomático e social (Tradução do autor).

Uma experiência que tem muito em comum com o bullying, especialmente a característica da repetição, mas que se diferenciaria dele posto que se realiza através das relações hierárquicas. No assédio, teríamos uma dinâmica vertical, de cima para baixo, na relação do chefe com o subordinado, enquanto que o bullying é, conceitualmente, um tipo de violência que ocorre entre pares, em uma dinâmica horizontal, portanto. A definição do fenômeno não é consensual, todavia. Alguns autores ${ }^{33}$ têm sublinhado que o assédio moral, ou mobbing ${ }^{34}$, pode ser de três tipos: ascendente, horizontal e descendente. O próprio Leymann ${ }^{35}$ afirma que o mobbing pode ser consequência da ação dos colegas de trabalho, caminho que torna a diferenciação com o fenômeno do bullying menos marcada.

As decorrências para as vítimas, independentemente da definição, podem ser devastadoras e costumam desestabilizá-las, depreciando sua qualidade de vida. As pesquisas indicam sérias

29 DUNCAN, Susan. Workplace Bullying and the Role Restorative Practices Can Play in Preventing and Addressing the Problem, p. 2335.

30 LUTGEN-SANDVIK, P. TRACY, S. J., \& ALBERTS, J. K. Burned by bullying in the American workplace: Prevalence, perception, degree, and impact. Journal of Management Studies, 44, pp.837-862, 2007. Disponível em: <https:// www.sarahjtracy.com/wp-content/uploads/2013/07/Lutgen-Tracy-Alberts-Burned-by-bullying.pdf>, Acesso em: 11/01/2020.

31 LUTGEN-SANDVIK, P. The communicative cycle of employee emotional abuse: Generation and regeneration of workplace mistreatment. Management Communication Quarterly, 16, pp. 471-501, 2003. Disponível em: $<$ https://www.natcom.org/sites/default/files/pages/NCA_Anti-Bullying_Resources_Lutgen-Sandvik_2.pdf>. Acesso em: 11/01/2020.

32 LEYMANN, Heiz. Mobbing and psychological terror at workplaces. Violence and Victims, 5, 119-126, 1990, p. 120. Disponível em: <http://www.mobbingportal.com/LeymannV\&V1990(3).pdf>. Acesso em: 03/09/2019.

33 GUIMARÃES, Liliana Andolpho Magalhães e RIMOLI, Adriana Odalia. "Mobbing" (Assédio Psicológico) no Trabalho: Uma Síndrome Psicossocial Multidimensional. Psicologia: Teoria e Pesquisa, Vol. 22 n. 2, 2006, pp. 183-192.

34 O conceito se originou de estudos de Niko Tinbergen e Konrad Lorenz com gaivotas e gansos. Tornou-se comum designar o assédio moral com expressões como: Harcèlement moral (França), Molestie Psicologiche (Itália), Bullying, Bossing e Harassment (UK, Austrália), Mobbing (EUA, Países nórdicos, bálticos e da Europa Central), Murahachibu (Japão), Coacção Moral (Portugal), Acoso Moral, Acoso Psicológico ou Psicoterrorismo (países hispânicos).apud: GUIMARÃES, Liliana Andolpho Magalhães e RIMOLI, Adriana Odalia. "Mobbing" (Assédio Psicológico) no Trabalho: Uma Síndrome Psicossocial Multidimensional, p. 184.

35 LEYMANN, Heiz. Mobbing and psychological terror at workplaces. Violence and Victims, p.119. 


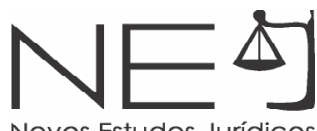

repercussões à saúde das vítimas. Insônia, melancolia e apatia são sintomas frequentes ${ }^{36}$. Cerca de 10 a $15 \%$ dos casos de suicídio na Suécia ocorrem por conta de processos de mobbing ${ }^{37}$.

Não raro, observa-se que as vítimas são desvinculadas dos seus pares, porque a ação perversa do agressor costuma ser, de alguma forma, reforçada pelos colegas, o que aumenta o sofrimento dos atingidos, tratados como "merecedores" do desprezo coletivo, o que reforça o processo de isolamento das vítimas. Leymann ${ }^{38}$ descreve quatro fases do processo de assédio moral no trabalho. A primeira delas é a do "Incidente Crítico Original" (Original Critical Incident). Trata-se do momento que irá desencadear o processo, normalmente vinculado a uma diferença ou a um conflito no ambiente de trabalho. Logo depois, instala-se a segunda fase, chamada de "Assédio e estigmatização" (Mobbing and Stigmatizing), na qual a reputação da vítima começa a ser atacada, onde ela passa a receber críticas insistentes e repetidas. É comum que as vítimas não consigam mais se expressar livremente e que os colegas evitem Ihe dirigir a palavra. Elas são, assim, isoladas e tratadas como se fossem invisíveis; já não recebem mais tarefas ou passam a receber trabalhos sem sentido. Por fim, recebem ameaças de violência ou mesmo são agredidas fisicamente. A terceira fase é definida como a da "Gestão de pessoal" (Personnel Administration). Trata-se do momento em que a situação se transforma, oficialmente, em um "caso" para a administração. É muito comum que, nessa etapa, o administrador assuma os preconceitos do grupo e que o problema todo passe a ser tratado como consequência de um desvio de personalidade da vítima. A quarta e última fase é a da "Expulsão" (Expulsion). Nesse ponto, a vítima já passou por vários períodos de licença médica, já foi rebaixada em suas funções e a saída do emprego aparece como uma resultante "natural" do processo.

Diante da gravidade do fenômeno do assédio moral no trabalho e de sua incidência, será possível trata-lo e mesmo prevenir sua ocorrência a partir de projetos restaurativos no interior das empresas e instituições públicas?

\section{UMA POSSIBILIDADE PARA A JUSTIÇA RESTAURATIVA}

Em 16 de janeiro de 2013, o Canadá se tornou o primeiro país a ter uma orientação geral para os ambientes de trabalho. Integrado por diretrizes, ferramentas e pesquisas, tal orientação foi designada como "O Padrão Nacional do Canadá para Saúde e Segurança Psicológica no Local de Trabalho" (The National Standard of Canada for Psychological Health and Safety in the Workplace). A adesão às diretrizes é voluntária, a partir do reconhecimento das empresas e dos trabalhadores de que elas podem melhorar efetivamente a segurança de todos. No Canadá, 69\% das solicitações por invalidez de longo prazo estão vinculadas a problemas de saúde mental. Estima-se que o país tenha um custo anual de 51,8 bilhões de dólares com problemas de saúde mental, mas o chamado

36 BJÖRKQVIST, ÖSTERMAN \& HJELT-BÄCK, 1994; Quine, 1999, apud: GUIMARÃES, Liliana Andolpho Magalhães e RIMOLI, Adriana Odalia. "Mobbing" (Assédio Psicológico) no Trabalho: Uma Síndrome Psicossocial Multidimensional, p.188.

37 LEYMANN, Heiz. Mobbing and psychological terror at workplaces. p.122.

38 LEYMANN, Heiz. Mobbing and psychological terror at workplaces. pp.121-122. 
"presenteísmo", fenômeno que designa a presença física no trabalho sem engajamento real custaria $150 \%$ mais do que as faltas ao trabalho ${ }^{39}$. Problemas de saúde mental relacionados ao trabalho são, como regra, muito expressivos. Segundo Rouquayrol ${ }^{40}$, eles foram responsáveis por 14,2\% das aposentadorias por invalidez e por 9,1\% das causas de auxílio-doença na década de 1980.

Para se pensar a justiça restaurativa nos ambientes de trabalho e desenvolver seu potencial quanto ao assédio moral, é preciso, preliminarmente, afastar uma visão limitadora que situa as abordagens restaurativas de forma reativa. Nessa moldura, a justiça restaurativa é concebida apenas como uma resposta a um conflito. O momento em que acionamos os mecanismos da justiça restaurativa para tentar tratar um problema já instalado constitui, com efeito, o ponto mais visível e marcante da abordagem. A justiça restaurativa, entretanto, pode ser mais do que isso. Além dos momentos formais que tendem a produzir impactos evidentes, a visão restaurativa envolve também determinadas práticas informais que podem produzir um impacto cumulativo ${ }^{41}$. Nesse sentido, autores $^{42}$ têm empregado a expressão "organização restaurativa" para definir uma instituição cujos princípios e normas são orientadas pelos princípios da justiça restaurativa. No cerne do novo modelo há uma cena pública (um círculo restaurativo, por exemplo) onde as pessoas expressam livremente suas emoções. Particularmente importante é a chance de que todos possam falar e serem ouvidos em um espaço institucionalizado, notadamente as vítimas em um contexto de tentativa de restauração. Possibilidades do tipo afetam a natureza das relações no grupo e tendem a estimular posturas solidárias. A confiança no ambiente de trabalho e a compreensão dos problemas enfrentados pelas pessoas que convivem diariamente facilitam a ação cooperativa ${ }^{43}$.

Neste sentido, determinadas posturas, cuidados e práticas de natureza restaurativa devem integrar o cotidiano do ambiente de trabalho como, por exemplo, o hábito de receber e de fazer elogios significativos, não formais; o cuidado de não fazer comentários preconceituosos ou intolerantes; a prática de discutir em grupo os principais temas, antes da tomada de decisões; o estímulo à iniciativa individual e à liberdade de expressão; o desenvolvimento das capacidades empáticas e o cuidado de evitar pré-julgamentos etc. Duncan ${ }^{44}$, a propósito, lembra que muitas empresas têm adotado tais cuidados além de ferramentas especiais para promover comunidade e contrastar aspectos negativos das tradições culturais mais associados à exclusão. Para reduzir a agressividade e evitar interrupções

39 COLDWELL, S.J., Addressing workplace bullying and harassment in Canada, research, legislation, and stakeholder overview: profiling a union program, Jilpt Report No. 12. The Japan Institute for Labour Policy and Training, 2013. Disponível em: <https://www.jil.go.jp/english/reports/documents/jilpt-reports/no.12_canada.pdf>. Acesso em: 28/08/2019.

40 ROUQUAYROL, Maria Zélia. Epidemiologia \& saúde. 4. ed. Rio de Janeiro: Medsi, 1993, p.392.

41 MCCOLD \& WACHTEL, 2001, apud: WACHTEI, Ted. Defining Restorative. International Justice for Restorative Practice, 2016, p.03. Disponível em: <https://www.iirp.edu/images/pdf/Defining-Restorative_Nov-2016.pdf>. Acesso em: 17/10/2019.

42 PAUL, G. D., and RIFORGIATE, S. "Putting on a happy face", getting back to work," and "letting it go": Traditional and restorative justice understandings of emotions at work. Electronic Journal of Communication, 2015. Disponível em: <https://krex.k-state.edu/dspace/handle/2097/28715>. Acesso em: 05/01/2020.

43 COHEN \& PRUSAK, 2011, apud WACHTEI, Ted. Defining Restorative, p. 01.

44 DUNCAN, Susan. Workplace Bullying and the Role Restorative Practices Can Play in Preventing and Addressing the Problem, p. 2352. 
na fala das pessoas, por exemplo, técnicas como o uso de talking sticks ${ }^{45}$ têm sido utilizadas. As abordagens restaurativas, em sua dupla dimensão - preventiva e curativa, tendem a beneficiar não apenas as pessoas que convivem no espaço de trabalho, mas o trabalho em si mesmo e, portanto, as organizações e as empresas. Reprimir sentimentos negativos como rancor, medo, raiva, pode resultar em uma piora da performance organizacional ${ }^{46}$. A experiência de integrar encontros de justiça restaurativa, em contrapartida, permite que essas emoções venham à tona e sejam ressignificadas pelo compartilhamento. Nessa linha, Daborah Kidder ${ }^{47}$, amparada em evidências de estudos empíricos, sustenta que a participação em encontros restaurativos faz com que as pessoas desenvolvam suas habilidades cooperativas e a capacidade de lidar com disputas pessoais, além de aumentar a empatia, prevenindo conflitos. A autora sintetiza esse processo com uma metáfora:

É possível visualizar as inter-relações no trabalho como um músculo. Para que os músculos sejam saudáveis e fortes, eles precisam ser exercitados, treinados e desafiados. Se o músculo for tensionado em demasia, se romperá e, talvez, nunca se recupere. Quando se permite que os conflitos interpessoais escapem ao controle, isso pode prejudicar permanentemente a relação. No entanto, pequenas rupturas no tecido muscular o tornam mais forte, enquanto a ausência de exercício o torna fraco. Os conflitos interpessoais, se tratados ao seu início, são como pequenas rupturas musculares. A justiça restaurativa oferece a oportunidade de treinamento para fortalecer as relações interpessoais, aumentando a confiança e a saúde delas ${ }^{48}$.

A abordagem restaurativa no espaço de trabalho estimula as pessoas a aceitarem a responsabilidade por seus atos quando eles resultam em dano a alguém ou às relações com a equipe. Por esse caminho, se criam as condições para algum tipo de reparação, o que, muitas vezes, é alcançado com um pedido sincero de desculpas e pelo consequente perdão. A restauração, assim viabilizada, solidifica o grupo e permite a retomada das relações de trabalho em um patamar superior de humanização e aprendizagem.

Há, aqui, uma importante diferença de paradigma organizacional. As modernas organizações de empresas e instituições são regidas por normas positivadas, estatutos e códigos estritos. O modelo exige o cumprimento das regras e prevê a punição dos que as desrespeitam. Muito frequentemente, entretanto, a aplicação das diretivas burocráticas agrava os conflitos no ambiente de trabalho ou agrega sérios prejuízos às equipes. Os gestores mais sensíveis, intuindo esses riscos, tendem a relativizar a aplicação das normas, o que inaugura novos riscos como a possibilidade de

45 O recurso envolve o uso em muitas tribos antigas de um objeto, normalmente um bastão esculpido, cuja posse confere o direito à fala em reuniões comunitárias. Só quem está com o bastão tem o direito à palavra. Em algumas tribos, apenas os líderes podiam sustentar o bastão, em outras, o bastão circulava entre todos, assegurando que ninguém fosse interrompido em respeito ao ritual. Práticas semelhantes são ou já foram empregadas modernamente por outras instituições como, por exemplo, os escoteiros.

46 Apud KIDDER, Deborah L. Restorative justice: not "rights", but the right way to heal relationships at work. International Journal of Conflict Management, Vol. 18 Issue: 1, pp.4-22, 2007, p. 15.

47 Apud KIDDER, Deborah L. Restorative justice: not "rights", but the right way to heal relationships at work, p. 15.

48 KIDDER, Deborah L. Restorative justice: not "rights", but the right way to heal relationships at work, p. 16. 
favorecimentos e/ou perseguições funcionais. O fato é que a abordagem restaurativa pressupõe outro tipo de organização, mais flexível, mais dialógica e mais orientada para o fortalecimento das relações e dos resultados, algo que Fehr \& Gelfand ${ }^{49}$ chamaram de "organizações que perdoam" (forgiving organizations).

\section{CONSIDERAÇÕES FINAIS}

As pesquisas a respeito da aplicação da abordagem restaurativa nas relações de trabalho e, particularmente, em casos de assédio moral estão em seu início e ainda são raros os trabalhos com dados empíricos. Muito ainda precisará ser estudado para que se possa afirmar, com base em evidências, qual a efetividade da justiça restaurativa nesse espaço e quais as técnicas com maior potencialidade, entre aquelas possíveis, para a reparação moral. As evidências disponíveis sugerem, não obstante, um espaço viável e produtivo para a abordagem restaurativa, tanto no que toca ao tratamento de casos concretos de assédio quanto às possibilidades de prevenção.

Por certo, não se pode presumir que a restauração seja viável sempre e, tampouco, que situações graves de assédio moral deixem de exigir processos judiciais e reparações obtidas por força de sentenças da Justiça do Trabalho. Especialmente em países como o Brasil, onde se convive com padrões pouco civilizados no mercado de trabalho e onde ainda são frequentes casos de abuso praticados pelos empregadores contra os trabalhadores, menos razões ainda para se imaginar um cenário marcado pela responsabilidade, compreensão e solidariedade, pressupostos sem os quais a própria ideia de restauração perde o sentido.

Ainda assim, o novo paradigma, representado pela justiça restaurativa e suas possibilidades de afirmação da dignidade humana, parece oferecer aos gestores públicos e privados e aos trabalhadores uma ferramenta imprescindível capaz de evitar tensionamentos desnecessários no ambiente de trabalho, de fortalecer os grupos de profissionais que convivem diariamente e de diminuir a incidência de práticas e circunstâncias que produzem uma quantidade não desprezível de dor e infelicidade.

\section{REFERÊNCIAS DAS FONTES CITADAS}

ARISTÓTELES. Ética a Nicômaco. Brasília: UNB, 2001.

BENTHAM, Jeremy. Os pensadores. São Paulo: Abril Cultural, 1979.

BESEMER, Sytske and FARRINGTON, David P. Intergenerational transmission of criminal behaviour: Conviction trajectories of fathers and their children. European Journal of Criminology, Volume: 9 issue:2, 2012, pp. $120-141$. Disponível em: <http://journals.sagepub.com/doi/pdf/10.1177/1477370811422801 > . Acesso em: 05/01/2020.

BRADSHAW, William, ROSEBOROUGH, David and UMBREIT, Mark S. The Effect of Victim Offender Mediation on Juvenile Offender Recidivism: A Meta-Analysis, Conflict Resolution Quarterly, Volume 24, Issue 1, 2006, pp. 87-98.

49 FEHR, R., and GELFAND, M. J. The forgiving organization: A multilevel model of forgiveness at work. Academy of Management Review, 37, 2012, pp. 664-688. 


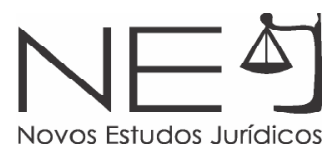

BRAITHWAITE, J. Restorative justice and corporate regulation, in: Weitekamp, G.M. and Herner, H.-J. (Eds), Restorative Justice in Context: International Practice and Directions, Willan Publishing, Portland, OR, 2003, pp. 161-72.

BRASIL. Ministério da Justiça e Segurança Pública. Departamento Penitenciário Nacional (Depen), DF, 2020. Disponível em: <https://www.gov.br/depen/pt-br/assuntos/noticias/depen-lanca-dados-do-sisdepen-doprimeiro-semestre-de-2020\#: :text=Bras\%C3\%ADlia\%2C\%2015\%2F10\%2F2020,penitenci\%C3\%A1rio\%20 brasileiro\%20\%C3\%A9\%20de\%20759.518>. Acesso em 20/10/2020.

BRASIL. Conselho Nacional de Justiça (CNJ), DF, Cidadania nos Presídios, s/d. Disponível em: <https://www.cnj. jus.br/sistema-carcerario/cidadania-nos-presidios/> Acesso em 24/04/2021.

COLDWELL, S.J., Addressing workplace bullying and harassment in Canada, research, legislation, and stakeholder overview: profiling a union program, Jilpt Report No. 12. The Japan Institute for Labour Policy and Training, 2013. Disponível em: <https://www.jil.go.jp/english/reports/documents/jilpt-reports/no.12_canada. pdf>. Acesso em: 28/08/2019.

DUNCAN, Susan. Workplace Bullying and the Role Restorative Practices Can Play in Preventing and Addressing the Problem. Industrial Law Journal, Vol. 32, 2011, p. 2331. Disponível em: <https://papers.ssrn.com/sol3/ papers.cfm?abstract_id=1916138>. Acesso em: 05/01/2020.

DWORKIN, Ronald. Levando os direitos a sério. São Paulo: Martins Fontes, 2010.

FARRINGTON, David. P. Families and crime. In: J.Q. Wilson \& J. Petersilia (eds.) Crime and public policy. Oxford University Press, 2011, pp. 130-157.

FEHR, R., and GELFAND, M. J. The forgiving organization: A multilevel model of forgiveness at work. Academy of Management Review, 37, 2012, pp. 664-688.

FERRAJOLI, Luigi. Derecho y Razón, Teoria del Garantismo Penal. Madrid, Editorial Trotta, 1977.

GOFFMAN, E. Estigma: notas sobre a manipulação da identidade deteriorada. Rio de Janeiro: LTC, 1988.

HUDSON, Barbara, MCEVOY, Kieran e MIKA, Harry. Introduction: Practice, Performance and Prospects for Restorative Justice, British Journal of Criminology, 42, 2002: pp. 469-475. Disponível em: <https://goo.gl/ FhRmjC > . Acesso em: 28/12/2019.

JOHNSTONE, Gerry. Restorative Justice: Ideas, Values, Debates. New York, Routledge, 2011.

KIDDER, Deborah L. Restorative justice: not "rights", but the right way to heal relationships at work. International Journal of Conflict Management, Vol. 18 Issue: 1, 2007, pp.4-22.

LEYMANN, Heiz. Mobbing and psychological terror at workplaces. Violence and Victims, 5, 1990, pp. 119126. Disponível em: <http://www.mobbingportal.com/LeymannV\&V1990(3).pdf>. Acesso em: 03/09/2019.

LLEWELLYN, Jennifer J. and HOWSE, Robert. Restaurative Justice: a Conceptual Framework, prepared for the Law Commission of Canada, 1999. Disponível em: <https://papers.ssrn.com/sol3/papers.cfm?abstract_ id $=2114291>$. Acesso em:17/10/2019.

LUTGEN-SANDVIK, P. The communicative cycle of employee emotional abuse: Generation and regeneration of workplace mistreatment. Management Communication Quarterly, 16, 2003, pp. 471-501. Disponível em: <https://www.natcom.org/sites/default/files/pages/NCA_Anti-Bullying_Resources_Lutgen-Sandvik_2.pdf >. Acesso em: 11/01/2020.

TRACY, S. J., \& ALBERTS, J. K. Burned by bullying in the American workplace: Prevalence, perception, degree, and impact. Journal of Management Studies, 44, 2007, pp.837-862. Disponível em: <https://www. sarahjtracy.com/wp-content/uploads/2013/07/Lutgen-Tracy-Alberts-Burned-by-bullying.pdf>. Acesso em: 11/01/2020. 
MACINTYRE, Alasdaire. After Virtue: A Study in Moral Theory. Notre Dame, In: University of Notre Dame Press. 1984.

MCCULLOUGH, M.E., RACHAL, K.C., SANDAGE, S.J., WORTHINGTON, E.L. JR, BROWN, S.W. and HIGHT, T.L. Interpersonal forgiving in close relationships: II. Theoretical elaboration and measurement, Journal of Personality and Social Psychology, Vol. 75, 1998, pp. 1586-603.

MARSHALL, F. Alternatives to Criminal Courts: The Potential For Non-Judicial Dispute Settlemen. Brookfield, VT: Gower Publishing Co., 1985.

NUGENT, William R, WILLIAMS, Mona \& UMBREIT, Mark S. Participation in Victim Offender Mediation and the Prevalence and Severity of Subsequent Delinquent Behavior: A Meta-Analysis. Utah Law Review, 137, 2003.

PAUL, G. D., and RIFORGIATE, S. "Putting on a happy face", getting back to work," and "letting it go": Traditional and restorative justice understandings of emotions at work. Electronic Journal of Communication, 2015. Disponível em: <https://krex.k-state.edu/dspace/handle/2097/28715>. Acesso em: 05/01/2020.

RAWLS, John, Uma Teoria da Justiça, São Paulo: Martins Fontes, 1997.

ROUQUAYROL, Maria Zélia. Epidemiologia \& saúde. 4. ed. Rio de Janeiro: Medsi, 1993.

SCHMITT, John and WARNER, Kris. Ex-offenders and the Labor Market. Washington, D.C. Center for Economic and Policy Research, 2010. Disponível em: <http://cepr.net/documents/publications/exoffenders-2010-11.pdf>. Acesso em: 18/11/2019.

SOUTH AFRICA. Truth and reconciliation commission. Report, vol. 1 e 2. Presented to President Nelson Mandela on 29 October 1998. Disponíveis, respectivamente, em: <https://www.sahistory.org.za/sites/default/ files/volume_1_1.pdf> e em < https://www.justice.gov.za/trc/report/finalreport/Volume\%202.pdf>. Acesso: $17 / 07 / 2019$.

STRANG, H. Repair or Revenge: Victims and Restorative Justice. Clarendon Press, Oxford, 2002.

TICKELL Shari e AKESTER, Kate. Restorative Justice, the way ahead. Justice publication, London, 2004. Disponível em: <https://justice.org.uk/restorative-justice-the-way-ahead/> Acesso em 05/01/2020.

UMBREIT, M.S. The Handbook of Victim Offender Mediation. Jossey-Bass, San Francisco, CA, 2001.

VAN DE RAKT, M.G.A. Two Generations of Crime: The Intergenerational Transmission of Criminal Convictions over the Life Course, Dissertation Radboud University Nijmegen, the Netherlands, 2011. Disponível em: <https://www.mariekevanderakt.nl/wp-content/uploads/2011/07/Two-Generations-of-Crime.pdf>. Acesso em: 18/11/2019.

WACHTEl, Ted. Defining Restorative. International Justice for Restorative Practice, 2016. Disponível em: <https://www.iirp.edu/images/pdf/Defining-Restorative_Nov-2016.pdf >. Acesso em: 17/10/2019.

ZAFFARONI, Eugenio Raúl. A questão criminal. Rio de Janeiro:Revan, 2013.

Recebido em: 12/01/2020

Aprovado em: 28/03/2021 